\title{
Romanian Professional Conduct of Mentors from Special Education Field Is Shaped by Their Communication Style?
}

\author{
Ionela Roxana Urea \\ Special Education Department, University of Bucharest, Bucharest, Romania.
}

How to cite this paper: Ionela Roxana Urea. (2021). Romanian Professional Conduct of Mentors from Special Education Field Is Shaped by Their Communication Style? The Educational Review, USA, 5(9), 309-315.

DOI: $10.26855 /$ er.2021.09.001

Received: August 8, 2021

Accepted: August 31, 2021

Published: September 13, 2021

Corresponding author: Ionela Roxana Urea, Special Education Department, University of Bucharest, Bucharest, Romania.

Email: roxanaurea@yahoo.com

\begin{abstract}
This paper is based on complex research on 90 mentors coming from special education field and it tries to underline the specific manner that communicational style shapes his/her professional conduct. We used "Questionnaire SC" (focused on revealing the communication styles); "The features of mentors' conduct questionnaire" (focused on revealing the main elements of mentors' professional conduct. It has two parts: The first part is focus to underlying the conduct's elements involve in the process of mentoring the pupils with disabilities; and the second part is focusing on pointing the elements of mentor' conduct manifest in mentoring process with students that are enrolled in bachelor training program in special education ); non-directive interviews. This study advances the idea that the mentor's professional conduct is direct linked with his/her communicational style and has different ways of manifestation in relation with the types of the students involved in mentoring process. The implications are essential for developing an efficient mentoring program in special education field.
\end{abstract}

\section{Keywords}

Communication style, mentor's professional conduct, mentoring, university students, professional brand

\section{Introduction}

The dynamic of the modern society has imposed new challenges for adult persons. Most of the challenges are related to the insertion of the adult into the labour market, and impose strategies for continuous development.

Mentoring is seen as a form of continuous personal development of adults, and lately the studies conducted are increasingly focused on streamlining the process of mentoring in terms of direct and indirect benefits obtained by both mentor and the mentees (Green-Powell, 2012); in terms of field specificity in which the mentor acts (Brooks, 2008; Hansford, Ehrich, \& Tennent, 2004), or in relation with specific typology of the mentees (Jassawalla, Asgary, \& Sashittal, 2006) or for developing specific networks (Bozionelos, 2019).

The present study approaches a penetration into the basic or derived processes connected with the wish to analyse the dimensions of mentors' conduct coming from special education in relation with their communication styles that define their personality. There is a real spiral of criticisms regarding the quality of the mentoring process and services provided with a real community awareness of the long-term implications resulting from the social policy. The analyses are focused on revealing the differences that are significant beyond the current information in the process of increasing the quality of the mentoring in special education field. 


\section{Conceptual analyses and background}

Human personality is constantly concern on founding the suitable methods, strategies in copying with demands associated with task in labour field. Special education is probably one of the most demanded sectors on education, due to the complexity and as the same time, unicity of each pupil with special education needs. Therefore, it become very clear, in the last decade, of the necessity of developing the mentoring process in close interdepending with teachers' continue professional and personal developing and longevity in the field (Dempsey, Kelly, \& Carty, 2009).

Mentoring is a form that supports professional development of persons. Initially, mentoring was assumed as an interaction between the mentor and mentee for aimed for sharing professional experience (Healy \& Welchert, 1990). The mentor usually was a person how had professional experience, in the field and also had certain age.

According to Ganesh, the two most common uses of the word mentoring are "to (a) describe a professional development relationship in which a more experienced participant assists a less experienced one in developing a career and (b) a guiding relationship between an adult and a young person focused on helping the youth realises his or her potential and perhaps overcome some barriers or challenges” (Ganesh \& All, 2015, p. 18).

The studies regarding to mentoring pointed that mentee recognized mentoring as a developmental tool and also as an opportunity to learn from more senior experienced colleagues. Gold, Thorpe, and Mumford (2010) identify those mentors can be a "door-opener" (Gold \& All, 2010, p. 249) for their mentees. Hughes and Sheerin (2016) claimed that mentors "can extoll the capabilities and achievements of their mentees to key decision makers in the organization" (Hughes \& Sheerin, 2016, p. 44).

The approaches of mentoring today changed. It is no longer only seeing as a simple interaction between mentors and mentee, it is seen as a relation that shapes mentee career (Bozionelos, 2019). Mentor "nowadays can be a co-worker or a peer, someone who is equal in status and in age” (Ambrosetti \& Dekkers, 2010, p. 42). Day by day, mentors have to deal with a serious challenge raised by the conflict between facing the adviser's role and the need to attend to heavy contractual workloads, performance targets and mentoring roles in tandem (Peiser, Ambrose, Burke, \& Davenport, 2018).

The relationship that is developed during the mentoring process is complex and most of all it has to be adjusted constantly. In 2014, Eller, Lev, and Feurer pointed out that " effective mentoring relationship involves: (1) open communication and accessibility; (2) goals and challenges; (3) passion and inspiration; (4) caring personal relationship; (5) mutual respect and trust; (6) exchange of knowledge; (7) independence and collaboration; and (8) role modelling” (Eller, Lev, \& Feurer, 2014, p. 805).

For developing an effective mentoring relationship, according to the European Competence Matrix "Mentor", the mentor should: 1) have a comprehensive knowledge of: - specific theories, models and methods of communication; specific conflict resolution theories, methods and models, principles and techniques of active listening; specific meanings of confidentiality; 2) have knowledge of the environment in which communication, active listening and conflict resolution take place, as well as the role of each party involved in this environment; 3 ) have a full range of cognitive and practical skills: communicate effectively with the mentor using practical communication tools and techniques; demonstrates active listening skills when communicating with the disciple, either on the phone or face to face, in order to solve various problems; finds, develops creative solutions to problems, taking into account the contribution of the mentor; help the mentee to become aware, clarify and prioritize personal and professional goals and priorities, to better understand his thoughts, feelings and options; 4) competence of creating and maintaining an effective working relationship with the mentor, which will contribute to the achievement of his professional goals; ensuring the well-being of the mentee and, if necessary, assisting in solving personal problems; reviewing and improving one's role in developing a working relationship that will maximize the results of the mentoring process (edu-mentoring.eu 'handbook' handbook_ro, p. 27).

The competences of mentors are developed during specific mentoring program at university level or during specific learning courses offered by private providers or organizations. The model used for training mentor is triangular which "includes mentor character virtues and intellectual/emotional abilities, as well as knowledge and skills (competencies) that are seen as expressions of training and experience” (Johnson, 2010, p. 139 cited by Ramirez, 2012, p. 58). It enchants also on communication skills that are practically essential in mentoring.

Mentoring is a process that is based and centered on all forms of communication (Farmer, 2005). Communication involves changing messages between two or more persons that have his/her own status and roles in organization (work field) and in society. The distance between participants' status and roles that occurs during the communication is diminish/increased by each participant's communication style. Communication style consists of individual characteristic features reflected in the communication act. Mainly, it refers to: specific ways of receiving/decoding the message; per- 
sonal qualities of processing/interpretation of messages; specific ways of expressing the response, the personal particularities of feedback. The one of the four communication styles: assertive, non-assertive, aggressive and manipulative is used in a dominant manner by each mentor and become a feature of his/her personality (Urea, 2015).

In an educational context, mentoring is a temporary collaborative relationship of two teachers based on the relationship between a more experienced teacher and a novice, or a beginner teacher. It is an essential relation where mentors use all the strategies that the communication style provides; it has his own dynamic and involves a constant learning process of mentor and mentee, constant adjusting and more of that it is not assimilated with career counselling process (Rosselot-Merrit \& Bloch, 2019); it involves a special leaning environment. The studies done in 2015 by Vinales revealed that in learning environment and also in special education, the majority of mentors is predominantly female and the role that they played role as facilitator.

In Romania, the statistical data revealed the mentors in special education are majority female (around $75 \%$ ). The mentor profession in education, in Romania, is regulated by Romanian National Law of Education no 1/2011 and by specific methodology. The documents point those mentors have to have great flexibility, as well as the existence of networks of mentors who work in a team and who can thus respond effectively to all requirements and situations. The role of the mentor model should not be understood in the sense of copying or imitation, but in that of facilitating learning in the sense of gaining independence, developing certain skills and understanding all the variables specific to the activity of the mentored persons.

In special education, in Romania, we noticed that the relation between mentors and mentee has three forms: a) between experienced teachers and beginner teachers/students; b) between experienced practitioners and beginning practitioners in field of therapeutically interventions, of counselling, of coaching; c) between experienced teachers and pupils with special education needs during professional orientation and career guidance process.

In our paper, we will be focus on the mentoring developed between experienced teachers and beginner teachers/students and on mentoring developed between experiences teachers and pupils with special education needs during professional orientation process and career guidance process. The experienced teachers are working in special schools and also developed mentoring relationships with students coming from University of Bucharest, Faculty of Psychology and Educational Sciences, Special Education Department.

\section{Methods.}

\subsection{Methods}

"The Questionnaire SC (Analysis of Communication Style-built in 2010 for Romanian mentors by R. Urea based on the S. Marcus's Questionnaire S. C). The test' features are: internal concistency $=0.834$, fidelity index $=0.727$.

“The features of mentors' conduct questionnaire” was created for mentors in 2017 for Romanian mentors that work in special schools. The questionnaire features are: internal concistency $=0.754$, fidelity index $=0.722$.

In our investigation, in order to analyse the collected data, we used IBM-SPSS 25 software.

\subsection{Participants}

We performed our research on: 90 mentors that works with children with deficiencies in special schools, coming from urban environments, aged $24-58$ years old (with average $=43.7$ years and median $=44.5$ years), $95.5 \%$ female and $4.5 \%$ male. The participation of the mentors was volunteers and based on their consent.

\subsection{Procedure}

In our research, we respected the General Data Protection Regulation of U.E—GDPR. Each investigated mentor was informed about: the aim of the research, the tasks that child has to fulfil during the research, about our intention to publish an article (by respecting the code of ethics) related the aspects that we investigated, about our intention in sharing the collected data with third parties. We asked and obtained the mentors' consent for collecting the data, for processing and analysing it, for publishing the article. We did not obtain their consents for sharing the collected data with third parties.

Our research had an initial testing procedure on 30 mentors coming from special education (Cronbach Alpha indexes $\alpha_{1}=0.682$

Our research had two major objectives: a) revealing the specific communication style of Romanian mentor coming from special education; b) revealing the specificity of the Romanian mentors' professional conduct that are working both with pupils with disabilities and with students from University. 


\section{Results}

\subsection{Investigation of specific communication style at mentor from special education}

The first objective of the research was aimed at revealing the specific communication style of Romanian mentor coming from special education. The data analyses process pointed that the distribution was uniform the skewness index values from 1.648 to 2.904 and with standard error of skewness from 0.968 of 1.631, and kurtosis index values from 0.987 to 1.904 , respectively standard error of kurtosis from 1.422 to 2.356

We are further presenting the data related to communication styles that our investigated mentor used in day-by-day mentor activity with 1) pupils with special education needs; 2) with students coming from Special education Department-University of Bucharest (Table 1).

Table 1. The mentors' communication style expressed in relation with type of beneficiaries

\begin{tabular}{ccccc}
\hline Types of beneficiaries & Non-assertive (\%) & Aggressive (\%) & Manipulative (\%) & Assertive (\%) \\
\hline Pupils with special education needs & 24.7 & 16.9 & 27 & 31.5 \\
Students coming from university & 5.6 & 0 & 2.2 & $\mathbf{9 2 . 1}$ \\
\hline
\end{tabular}

\subsection{Investigation of professional conduct of mentors from special education}

The second objective of the research was aimed at revealing the specific of professional conduct of our investigated mentor.

The data analyses process pointed that the distribution was uniform, the skewness index values from 1.621 to 2.432 and with standard error of skewness from 0.858 of 501.633, and kurtosis index values from 0.983 to 1.912, respectively standard error of kurtosis from 1.421 to 2.358 .

We analysed, on a Lickert' assessment scale with 5 levels ( 1 is the lowest and 5 is the highest), the mentors professional conduct manifested in relation with pupils with special education needs (see Table 2) and also in relation with the students coming from University of Bucharest (see Table 3).

Table 2. Mentors' professional conduct manifested with pupils with special education needs during professional orientation process and career guidance process

\begin{tabular}{|c|c|c|c|c|c|}
\hline \multirow{2}{*}{ Mentor's professional conduct (self-assessment) } & \multicolumn{5}{|c|}{ Levels of assessment (\%) } \\
\hline & Highest & High & Medium & Low & Lowest \\
\hline Specialized learning strategies for deficient pupils & 75.3 & 22.5 & 2.2 & - & - \\
\hline Communication with pupils with special education need & 78.2 & 20.8 & 1.1 & & \\
\hline Conflict management activities & 46.1 & 42.7 & 9 & 2.2 & \\
\hline Specialized assessment strategies for deficient pupils & 53.4 & 38.6 & 8 & & \\
\hline Creating materials for supporting the deficient pupils during the learning process & 52.8 & 41.6 & 5.6 & & \\
\hline Global mentor's professional conduct & 63.7 & 26.9 & 9.4 & & \\
\hline
\end{tabular}

Table 3. Mentors’ professional conduct manifested with students coming from University of Bucharest

\begin{tabular}{cccc}
\hline Mentor's professional conduct & \multicolumn{3}{c}{ Levels of assessment (\%) } \\
$\begin{array}{c}\text { Planning, organizing and analysing the university students' activity during the } \\
\text { internship }\end{array}$ & 58.4 & 37.1 & 4.5 \\
Monitoring the university students' activity & High & Medium Low Lowest \\
\hline Career' counselling of university students & 35.2 & 50 & 14.8 \\
Assessing university students' activity & 58 & 23.9 & 18.1 \\
Identifying the university students' training needs & 43.2 & 47.1 & 9.1 \\
Global mentor professional conduct & 52.8 & 41.6 & 5.6 \\
\hline
\end{tabular}




\section{Discussions}

\subsection{Investigation of specific communication style at Romanian mentors from special education}

From the data collected in Table 1, we found that the majority of mentors that are working in special education field have as communication style the assertive type, regardless with the types that they are dealing with. It means that our mentors are able to express direct and clear their opinions without harming others; the ability to pursue one's own interests without violating the needs of others. They know how to listen and are willing to understand.

A closer look to the assertive communication style that our mentors used with different subjects, allowed us to say that: a) in relation with pupils with special education need signified in fact the accessibility process of messages to the pupils with deficiencies according with their level of deficiency and to their potential; b) in relation with university students, it serve to the purpose of the university concepts training: gaining practice/professional experience focus on reaching the interventional tasks without wasting resources involved in.

Based on statistical data analysis (t test for independent sample), we found that the data analysed, are significant (see Table 4).

Table 4. The t test on mentor' communicational style used in relation with different subjects

\begin{tabular}{|c|c|c|c|c|c|c|c|}
\hline \multirow[b]{2}{*}{ Lot type } & & \multicolumn{6}{|c|}{ Test Value $=0$} \\
\hline & & $\mathrm{t}$ & $\mathrm{df}$ & $\begin{array}{c}\text { Sig. } \\
\text { (2-tailed) }\end{array}$ & $\begin{array}{l}\text { Mean Dif- } \\
\text { ference }\end{array}$ & $\begin{array}{r}95 \% \text { Confi } \\
\text { the } 1\end{array}$ & $\begin{array}{l}\text { nterval of } \\
\text { ice }\end{array}$ \\
\hline \multirow{4}{*}{$\begin{array}{l}\text { Mentors’ pro- } \\
\text { fessional con- } \\
\text { duct n relation } \\
\text { with pupils with } \\
\text { Special educa- } \\
\text { tion need }\end{array}$} & $\begin{array}{l}\text { Non-assertive com- } \\
\text { munication style }\end{array}$ & 11.225 & 90 & 0.000 & 5.6000 & 2.044 & 6.729 \\
\hline & $\begin{array}{l}\text { Aggressive commu- } \\
\text { nication style }\end{array}$ & 16.174 & 90 & 0.000 & 9.400 & 2.09 & 7.121 \\
\hline & $\begin{array}{l}\text { Manipulative com- } \\
\text { munication style }\end{array}$ & 12.300 & 90 & 0.000 & 8.744 & 1.022 & 6.994 \\
\hline & $\begin{array}{l}\text { Assertive commu- } \\
\text { nication style }\end{array}$ & 11.356 & 90 & 0.000 & 6.600 & 3.4022 & 6.788 \\
\hline \multirow{4}{*}{$\begin{array}{l}\text { Mentors' pro- } \\
\text { fessional con- } \\
\text { duct in relation } \\
\text { with university' } \\
\text { students }\end{array}$} & $\begin{array}{l}\text { Non-assertive com- } \\
\text { munication style }\end{array}$ & 9.842 & 90 & 0.000 & 5.3000 & 4.082 & 8.744 \\
\hline & $\begin{array}{l}\text { Aggressive commu- } \\
\text { nication style }\end{array}$ & 8.981 & 90 & 0.000 & 6.8000 & 1.069 & 4.224 \\
\hline & $\begin{array}{l}\text { Manipulative com- } \\
\text { munication style }\end{array}$ & 12.362 & 90 & 0.000 & 8.200 & 6.70 & 9.702 \\
\hline & $\begin{array}{l}\text { Assertive commu- } \\
\text { nication style }\end{array}$ & 8.268 & 90 & 0.000 & 5.200 & 3.78 & 14.788 \\
\hline
\end{tabular}

Taking all the findings into consideration we can say that the mentor's communicational style is constantly shaped by the trainee's features and is managed according with the mentoring's goals and resources involved in.

\subsection{Investigation of professional conduct of Romanian mentors from special education}

5.2.1. Investigation of professional conduct of mentors from special education in relation with pupils with special education needs

The data synthesized in Table 2 reflects the mentor' professional conduct in relation with pupils with special educational needs is sensitive to conflict management activities. It signified that the mentors' abilities in management conflict situation have to be flexible and adaptive to all the aspects that conflict is related. But mentors, most of them, do not have functional skills in mediating conflicts. So, in this case, he/she uses communication skills as copying mechanism in order to prevent escalating conflicts and in the same time for maintaining the secure educational climate for pupils with special needs.

The other components of mentor's professional conduct manifested in relation with pupils with special needs that we investigated are on highest level and reflect an integrative manner of performing the mentoring process.

The statistical data analyses pointed that the assertive communication style has a very significant impact on general mentor' professional conduct manifested in relation with pupils with special needs (impact $=0.845)$; impact generated by the mentor' teaching style and mentor' position in organization among other teachers. 
5.2.2. Investigation of professional conduct of mentors from special education in relation with university' students

The data presented in Table 3 show the mentor's professional conduct in relation with university students has a specific manner of manifestation. First of all, the skills associated to mentors professional conduct manifested in relation with university students have a lower weight at a high level compared to those evaluated in relation with pupils with special education needs.

Why is happening that?

A possible answer that can be produced to the question above is that the mentor's professional conduct is manifested in relation with pupils with special needs day by day. In this manner, certain relational patterns have been developed by each mentor that increased the quality of the mentoring process and its efficiency.

The mentoring activities with university' students are not developed day by day. Besides the educational goals, in this case, the mentor has also to deal, with the university students' interests, with their vision regarding the role, associated status that will play/have when they will become psycho-pedagogues and, sometime possible tensions can be arise between mentors and university' students. These tensions have to be resolve very quickly; otherwise, the mentoring's process can be compromised (the quality of the mentoring process will be decreased).

Secondly, we noticed (from data presented in Table 3) that the mentor' professional conducted manifested in relation with university students is sensitive to monitoring the university students' activity and to assessing university students' activity. It means that mentor effectively approaches those to activities as a hole and makes guidance during the assessments stage. It is not wrong that he/she does that. But, in this manner, he/she overlooks to develop at trainees (university students) the long term-planification skills and reduce the operationally of the other skills.

Last but not least, we noticed that the majority investigated mentors are able to identifying the university students training needs at highest level. Why this thing is important?

Analysing all the data and the answers from non-directive interviews, we found five reasons that allowed us to realize the importance of " identifying the university' students training needs" activity: a) it allows to mentor to create a specific mentoring program address to university' students according to their training needs; b) it allows the mentor to have SMART objectives on mentoring activities; c) it allows a direct, flexible relation with university' students; d) it allows a proper usage of all the resources involved in mentoring; e) generate satisfaction of university' students regarding teaching pupils with special needs and valorising their potential.

The statistical data analyses pointed that the assertive communication style has a very significant impact on general mentor's professional conduct manifested in relation with university students (impact $=0.871$ ); impact generated by the mentor's experience and his/her professional brand.

We can say that the mentor's professional conduct is clear the expression of the mentoring patterns that mentor developed according with his/her experience level and shapes the dynamic of the process.

\section{Conclusions and recommendations}

This research had the goal to reveal specific manner in which the mentor' communication style influences his/her professional conduct.

In our investigation we used specific and adapted instruments.

With the help of statistical analysis, we found that the Cronbach's Alpha is 0.862 .

We found that:

1) The communication style is used by mentor in relation with the purpose of the communication and with the students' features.

2) There are different ways of how mentor' professional conduct is reflected in day-by-day activities with pupils with special educational needs and scheduled activities with university' students;

3) The mentor' professional conduct is a clear expression of his/her professional brand.

4) The assumption of our research was confirmed.

Our findings can be useful for teacher in order to:

a) develop secure mentoring climate for pupils with special educational needs;

b) establish a partnership between mentor and university students during the mentoring process;

c) establish a partnership between mentor and parents of pupils with special needs during the mentoring process;

d) create efficient instruments for monitoring university students' activities

e) create efficient instruments for assessing university students' activities;

f) encourage the exchanging of methods, strategies between mentors that work with university students; 
g) increase the awareness of mentoring activities in education and social environment.

We also can use the previous conclusions for:

- generate mentor's satisfaction regarding the experience that is passing on to young generation;

- improving the quality of mentoring process provided to different types of students;

- increase the awareness of mentoring activities in education and social environment;

- developing strategies to combat the phenomena of exclusion from the different social groups of people with intellectual disabilities;

- stimulating the participation of people with intellectual disabilities to community’s activities.

\section{References}

Ambrosetti, A. and Dekkers, J. (2010). The Interconnectedness of the Roles of Mentors and Mentees in Pre-service Teacher Education Mentoring Relationships. Australian Journal of Teacher Education, 35(6): 42-55. http://dx.doi.org/10.14221/ ajte.2010v35n6.3

Bozionelos, N. (2019). Mentorship and developmental networks. In Gunz, H., Lazarova, M., \& Mayrhofer, W. (Eds.), The Routledge Companion to Career Studies (pp. 201-218). New York: Routledge.

Brooks, J. (2018). Let’s get serious about mentoring. British Dent Journal, 224, 72. https://doi.org/10.1038/sj.bdj.2018.39.

Dempsey, I., Kelly, M. A., and Carty, B. (2009). Mentoring Early Career Special Education Teachers. Australian Journal of Education, 53(3): 294-305.

Eller, L. S., Lev, E. L., and Feurer, A. (2014). Key components of an effective mentoring relationship: a qualitative study. Nurse Educ Today, 34(5): 815-820. https://doi:10.1016/j.nedt.2013.07.020.

Farmer, B. (2005). Mentoring Communication. Review of Communication, 5: 2-3, 138-144. https://doi: 10.1080/15358590500297003.

Ganesh, A., Bozas, A., Subban, M., and Munapo, E. (2015). The benefits of mentoring and coaching in the public sector. Journal of Governance and Regulation, 4(3), 16-29, Available from: https://www.researchgate.net/publication/311503509_The _benefits_of_mentoring_and_coaching_in_the_public_sector [accessed Dec 05 2019]. practice. in: Educational Researcher, 19(9): 7-21.

Green-Powell, P. (2012). The Rewards of Mentoring. US-China Education Review, B1(2012), 99-106. https://files.eric.ed. gov/fulltext/ED531660.pdf.

Hansford, B. C., Ehrich, L. C., and Tennent, L. (2004). Formal Mentoring Programs in Education and other Professions: A Review of the Literature. Educational Administration Quarterly, 40(4): pp. 518-540. https://doi:10.1177/0013161X04267118.

Healy, C. C. and Welchert, A. J. (1990). Mentoring Relations: A Definition to Advance Research and Practice. Educational Researchers, 19(9): 17-21.

Hughes, C. and Sheerin, C. (2016). Reflections on the Relationship Between Mentoring, Female Development and Career Progression: Investment Management Versus Human Resource Management. International Journal of HRD Practice, Policy and Research, 1(2): 41-54. https://doi: 10.22324/ijhrdppr.1.115.

Jassawalla, A. R., Asgary, N., and Sashittal, H. (2006). Managing expatriate: The role of mentors. International Journal of Commerce and Management, 16(2): 130-140. https://doi: 10.1108/10569210680000212.

Peiser, G., Ambrose, J., Burke, B., and Davenport, J. (2018). The role of the mentor in professional knowledge development across four professions. International Journal of Mentoring and Coaching in Education, 7(1): 2-18. https://doi.org/10.1108/IJMCE-07-2017-0052Permanent link to this document:https://doi.org/10.1108/IJMCE-07-2017-005.

Ramirez, J. J. (2012). The Intentional Mentor: Effective Mentorship of Undergraduate Science Students. Journal of Undergraduate Neuroscience Education, 11(1): A55-A63.

Rosselot-Merrit, J. and Bloch, J. (2019). Mentoring in Business and Professional Communication: Case Study of a Multiyear Dynamic. Business and Professional Communication, 83(1): 5-33. https://doi: 10.1177/2329490619885891ua.

Urea, R. (2015). Dimensions of social communication at pupils with mental deficiency. Saarbrucken: Lap Lambert Academinc Publishing,

Vinales, J. J. (2015). The Learning Environment and Learning Styles: A Guide for Mentors. Br J Nurs., 13, 24(8): 454-7. https://doi: 10.12968/bjon.2015.24.8.454. 